\title{
Hemoptysis after CardioSEAL device embolization of a venous collateral after the Fontan operation
}

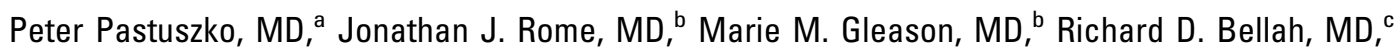 \\ Lisa M. Montenegro, MD, ${ }^{d}$ and J. William Gaynor, MD, ${ }^{a}$ Philadelphia, $\mathrm{Pa}$
}

$\mathrm{T}$ ranscatheter closure of septal defects and other vascular structures in children is a rapidly evolving field with a growing number of applications for the currently available devices. Despite the widely accepted use of these closure devices for lesions such as atrial septal defects and patent ductus arteriosus, their use in the treatment of other defects is limited. Consequently, little is known about the associated risks and complications. We present here a case of a delayed complication of airway erosion from a CardioSEAL device (NMT Medical, Boston, Mass) used to close a large anomalous systemic to pulmonary venous channel after the Fontan operation.

\section{Clinical Summary}

An 18-year-old man with a functional single ventricle presented with recurrent hemoptysis. He had undergone staged reconstructive surgery with Fontan completion at 18 months of age. At the age of 13 years, he was noted to have decreased arterial oxygen saturations. Cardiac catheterization revealed a large decompressing vein from the superior vena cava to the right pulmonary vein. Criteria were met for entry into the CardioSEAL High Risk Device Trial (sponsor: Children's Hospital, Boston, Mass), and informed consent was obtained. The vascular channel was closed with a CardioSEAL device. Five years later, he presented initially with a cough and subsequently with hemoptysis and recurrent desaturation. Catheterization revealed a left pulmonary artery stenosis, but no cause for the hemoptysis. Several weeks later he presented with recurrent hemoptysis. The chest $\mathrm{x}$-ray film was essentially unremarkable, but a computed tomographic scan revealed erosion of the CardioSEAL device into the right main-stem bronchus (Figure 1). Bronchoscopy confirmed the erosion of the device through the lumen of the right upper lobe bronchus, nearly obstructing the right main-stem bronchus. The device was removed through a right thoracotomy. There was extensive inflammation and scarring, and the device was adherent to the right pulmonary artery. Because of

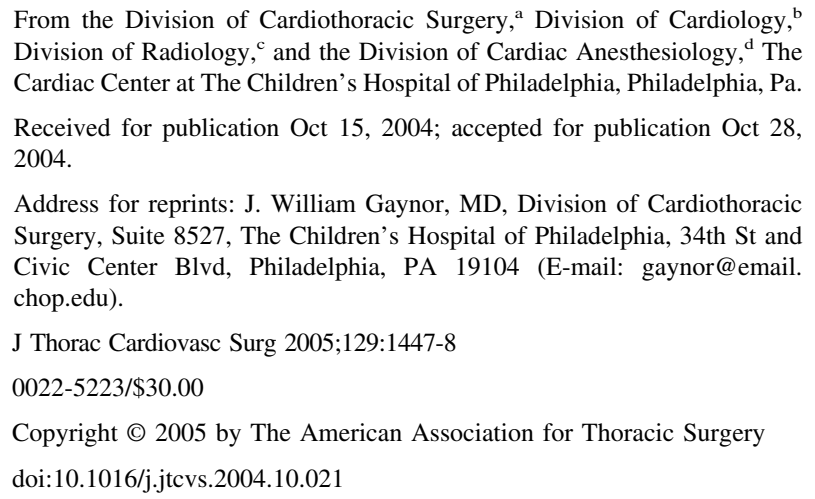

Address for reprints: J. William Gaynor, MD, Division of Cardiothoracic Surgery, Suite 8527, The Children's Hospital of Philadelphia, 34th St and Civic Center Blvd, Philadelphia, PA 19104 (E-mail: gaynor@email. chop.edu).

J Thorac Cardiovasc Surg 2005;129:1447-8

$0022-5223 / \$ 30.00$

Copyright $\odot 2005$ by The American Association for Thoracic Surgery doi:10.1016/j.jtcvs.2004.10.021

the dense adhesions, it was not possible to obtain proximal control of the pulmonary artery. Cardiopulmonary bypass support was used, and a right upper lobectomy with repair of the pulmonary artery was performed. On follow-up, there has been no hemoptysis 7 months after surgery.
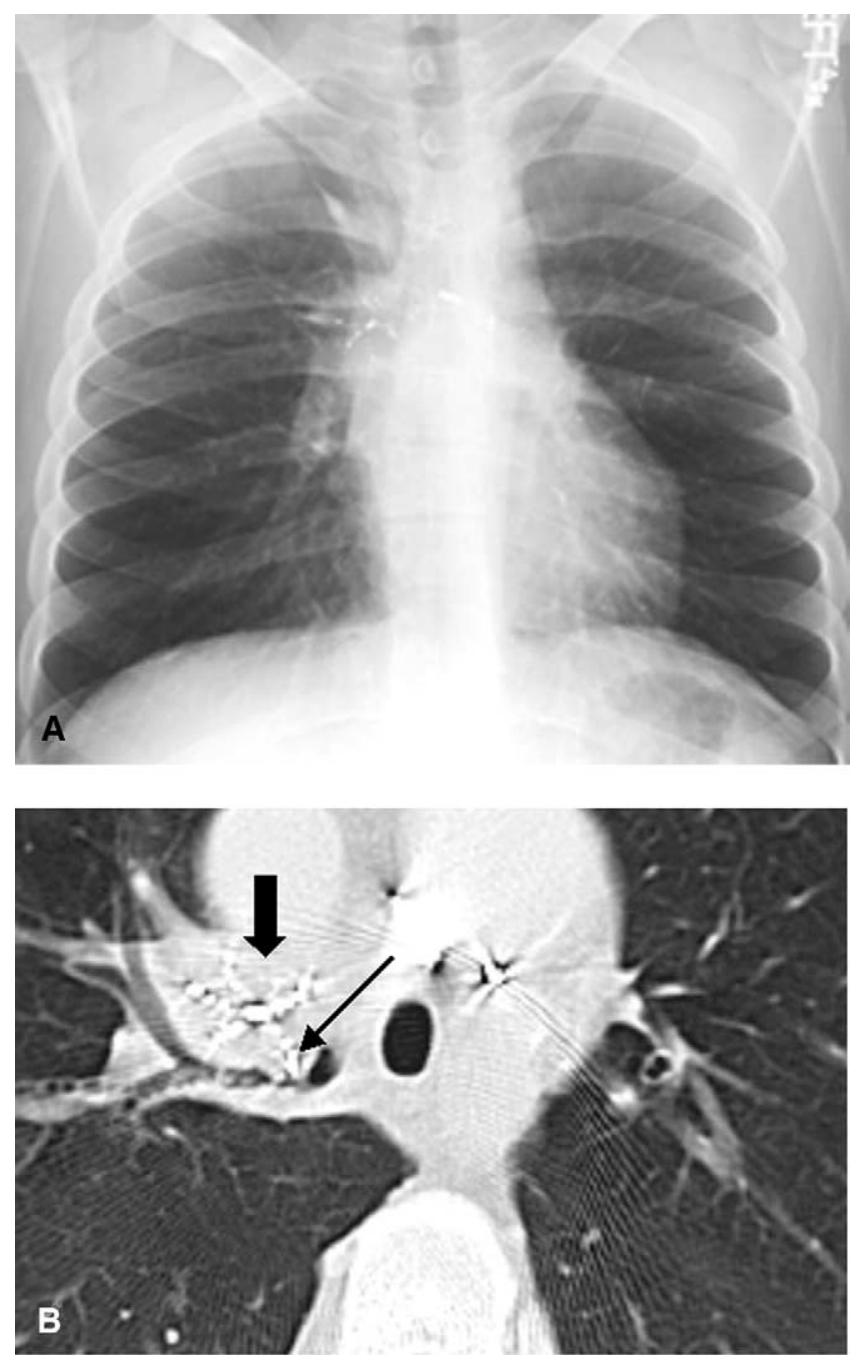

Figure 1. A, Chest x-ray film shows vascular occlusive device in right paratracheal area. B, Contrast computed tomography scan (magnified view) shows vascular occlusive device (short arrow) with posterior limb (long arrow) eroding into the right main bronchus. 


\section{Discussion}

There is extensive experience with the use of endovascular devices for closure of intracardiac defects and patent ductus arteriosus. However, there is little information on the use of these devices for intrapulmonary occlusions. The CardioSEAL double umbrella device (NMT Medical) was approved in the United States for closure of muscular ventricular septal defects in December 2001. Successful use of this device has been reported in occlusion of a large pulmonary arteriovenous malformation in an adult patient with hereditary hemorrhagic telangiectasia. ${ }^{1}$ In our patient this type of device was used to close an intrapulmonary vein. The procedure was successful; however, the patient returned 5 years later with hemoptysis secondary to erosion of the device into the right upper lobe bronchus. To our knowledge, this is the first reported case of such a complication. In a recent review of a group of 417 patients who underwent a device closure of secundum atrial septal defect, Chessa and associates $^{2}$ reported an $8.6 \%$ incidence of complications. The most common complication was a device malposition or embolization $(3.5 \%)$. Seven patients required surgical intervention after device embolization. No erosions were reported in this series; however, hemopericardium and fistula formation have been described after atrial septal defect closure. ${ }^{3,4}$ The mechanism of erosion is unknown, but it is likely that it is due at least in part to persistent pressure to the endovascular surface from a constrained device. In our case the arms of the CardioSEAL were partially collapsed in the vascular structure.

The use of stents, coils, and other intravascular devices has grown dramatically in the last several years. As their use increases, so does recognition of their limitations and the potential complications of migration and embolization. Intravascular foreign body migration is a well- documented phenomenon, particularly for intracardiac missiles and missile emboli. Previously, foreign body removal was advocated for most cases; however, a more selective approach has recently been advocated. ${ }^{5}$ The unstable nature of intravascular foreign bodies continues to be stressed.

The use of percutaneous interventional techniques for the treatment of congenital cardiac disease will continue to increase. However, the natural history of intravascular devices is not well known. Intravascular foreign objects have a tendency to erode into the surrounding structures and to migrate. As use of intravascular devices continues to expand, close follow-up of these patients is necessary.

\section{References}

1. Apostolopoulou SC, Kelekis NL, Papagiannis J, Hausdorf G, Rammos S. Transcatheter occlusion of a large pulmonary arteriovenous malformation with use of a Cardioseal device. J Vasc Interv Radiol. 2001;12:767-9.

2. Chessa M, Carminati M, Butera G, et al. Early and late complications associated with transcatheter occlusion of secundum atrial septal defect. J Am Coll Cardiol. 2002;39:1061-5.

3. Ewert P, Kretschmar O, Peters B, et al. Preliminary experience with a new $18 \mathrm{~mm}$ Amplatzer PFO occluder for small persistent foramen ovale. Catheter Cardiovasc Interv Aug. 2003;59:518-21.

4. Chun DS, Turrentine MW, Moustapha A, Hoyer MH. Development of aorta-to-right atrial fistula following closure of secundum atrial septal defect using the Amplatzer septal occluder. Catheter Cardiovasc Interv. 2003;58:246-51.

5. Symbas PN, Picone AL, Hatcher CR, Vlasis-Hale SE. Cardiac missiles. A review of the literature and personal experience. Ann Surg. 1990;211:639-48.

\title{
Tetralogy of Fallot and hypoplastic aortic arch: A novel perspective
}

\author{
David L. S. Morales, MD, Daniel J. DiBardino, MD, Wesley Vick, MD, Charles D. Fraser, Jr, MD, and \\ E. Dean McKenzie, MD, Houston, Tex
}

T etralogy of Fallot with coarctation of the aorta is a rare diagnosis that is counterintuitive to widely accepted theories of cardiac embryology. This arrangement of tetralogy of Fallot (TOF) with a left-sided obstructive lesion has only been reported in the literature in 9 previous patients. ${ }^{1,2} \mathrm{We}$ describe a unique variant of this unlikely association (TOF and a

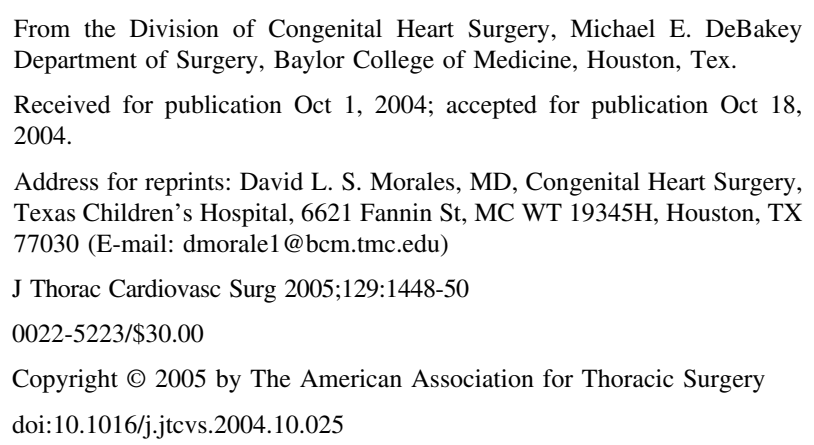

hypoplastic aortic arch) and discuss its possible embryology and morphogenesis.

\section{Clinical Summary}

A 4-month-old child, weighing $7 \mathrm{~kg}$, was diagnosed with TOF at birth. She was placed on beta-blocker therapy and monitored with oxygen saturations in the low 90s, despite severe right ventricular outflow tract (RVOT) obstruction (gradient of $64 \mathrm{~mm} \mathrm{Hg}$ ). Physical examination revealed the following blood pressures: right arm 83/40 $\mathrm{mm} \mathrm{Hg}$, left arm $89 / 39 \mathrm{~mm} \mathrm{Hg}$, and right leg $82 / 38 \mathrm{~mm} \mathrm{Hg}$, and a slight decrease in lower extremity pulses. A follow-up echocardiogram at 3 months revealed a large ascending aorta and a concern for aortic coarctation. Subsequent cardiac magnetic resonance imaging demonstrated TOF and a high right aortic arch with tubular hypoplasia and a small descending aorta with diastolic runoff (Figure 1). The narrowest segment $(0.25 \mathrm{~cm})$ was the distal arch between the right common carotid and right subclavian arteries.

At operation, there was an anterior malrotation of the dilated ascending aorta, a right aortic arch with mirror image branching, 